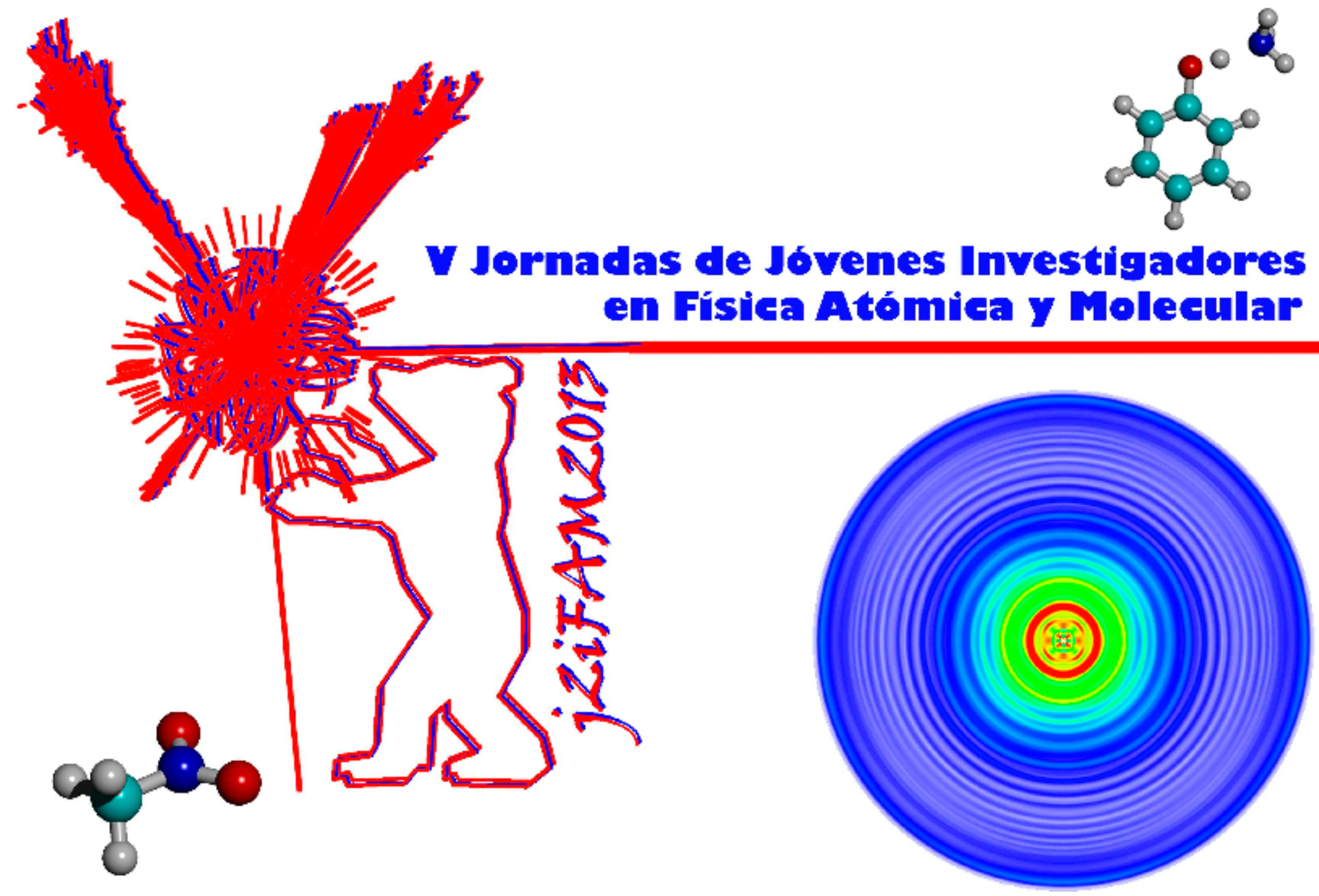

February, I 3 rd - I sth 2013 Madrid, Spain

Physies of Ageregates

Reaction Dynamics

Quantum Ghemistry

Surface Physies

Atomie and Molecular Gollisions
Ultracold Atoms and Molecules Canomaterial Seience Spectroseopy and Exeited States Quantum Information

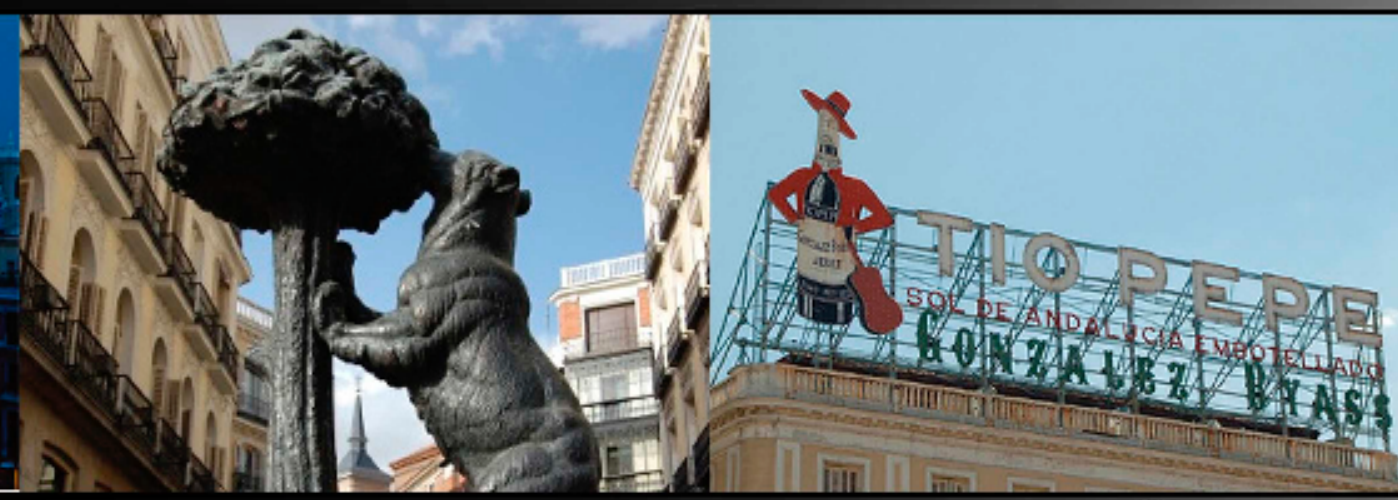

https//wrw.ucm.es/centros/webs/j2ifamv/

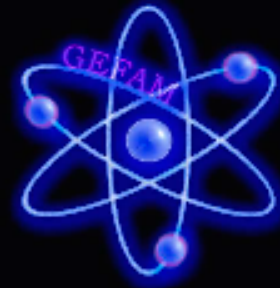

Salon de agtos

Faeultad de Gieneias Cuínietas UGM

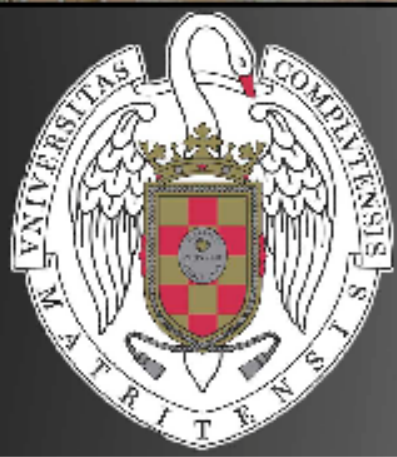




\section{Strong field control of predissociation dynamics}

G. Balerdi ${ }^{1}$, M.E. Corrales ${ }^{1}$, V. Loriot ${ }^{1,2}$, G. Gitzinger ${ }^{1,2}$, J. González-Vázquez ${ }^{1}$, I. R. Solá $^{1}$, R. de Nalda ${ }^{2}$, L. Bañares ${ }^{1}$

${ }^{1}$ Departamento de Química Física, Facultad de Ciencias Químicas (Unidad Asociada CSIC), Universidad Complutense de Madrid, 28040 Madrid, Spain

${ }^{2}$ Instituto de Química Física Rocasolano, CSIC, C/ Serrano 116, 28004 Madrid, Spain E-mail: garikoitz.bv@gmail.com

Strong field control scenarios are investigated in the $\mathrm{CH}_{3} \mathrm{I}$ predissociation dynamics at the origin of the second absorption B-band, in which state-selective electronic predissociation occurs through the crossing with a valence dissociative state [1]. Dynamic Stark control (DSC), which was recently demonstrated by Sussman et. al [2], and pump-dump strategies are shown capable of altering both the predissociation lifetime of the excited Rydberg state and the product branching ratio.

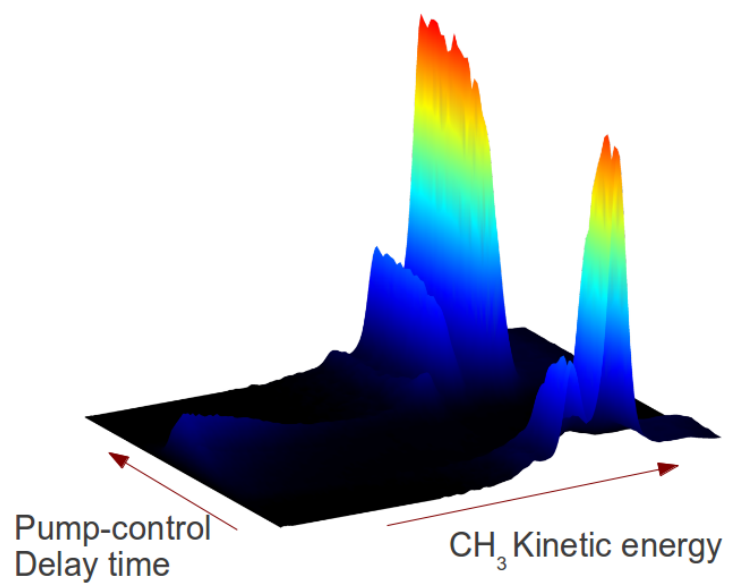

Figure 1. Speed distribution of the $\mathrm{CH}_{3}$ fragments generated after predissociation of $\mathrm{CH}_{3} \mathrm{I}$ as a function of the delay between the pump and control laser pulses. Supression of the photofagmentation is observed when the pulses are overlapped in time due to dynamic Stark shift (DSS)

[1 ] G. Gitzinger, M.E. Corrales, V. Loriot, G.A. Amaral, R. de Nalda and L. Bañares, J. Chem. Phys. 132, 234313(2010).

[2 ] B. J. Sussman, D. Townsend, M. Y. Ivanov and A. Stolow, Science, 314, 278(2006). 